\title{
A study on Promoting Non-English Major Students' Autonomous Learning through Metacognitive Strategy Training
}

\author{
Guo Dongping \\ Ningxia Vocational and Technical College, Yinchuan Ningxia750021, China \\ Ningxia Radio \& TV University, Yinchuan Ningxia 750002, China
}

\begin{abstract}
Improving Non-English major students' autonomous learning is a focus for the teachers in the high vocational and technical college. Furthermore, promoting students' autonomous learning through metcacognitive strategies training has been received increasing attention. The research reports an empirical study on the relationship between metacognitive strategies and English autonomous learning. Finally, the teaching experiment was proved to be feasible and valid.
\end{abstract}

Key words: metacognitive strategies; high vocational English; autonomous learning

\section{INTRODUCTION}

Holec introduced learner autonomy into language learning by describing it as "the ability to take charge of one's learning(1981:3).[1]"'In his view, autonomy is an ability, not an action., According to Littlewood (1996: 428),[2] an autonomous person "has an independent capacity to make and carry out the choices which govern his or her action." In his views, learners should take responsibility for their own learning both because "all learning can in any case only be carried out by the students themselves and also because they need to develop the ability to continue learning after the end of their formal education," and taking responsibility involves learners in "taking ownership (partial or total) of many processes which have traditionally belonged to the teacher, such as deciding on learning objectives, selecting learning methods and evaluating progress."

2. metacognitive strategies training and learner autonomy

O'Malley[3] et al conducted a research on 75 subjects enrolled in ESL program at secondary level in three mid-Atlantic suburban high schools in 1985. The subjects were randomly assigned and divided into three groups: cognitive group, metacognitive group, and control group. The cognitive group was trained in cognitive strategies, such as note-making and social strategies. The metacognitive group was, in addition, trained in metacognitive strategies, As a result, no improvement was found on listening and vocabulary tasks. But on the speaking task, the metacognitive group improved significantly more than the other tvvo, with the control group improved least. Ji Kangli(2002),[5] Chinese scholar, conducted a study of metacognitive strategy training on reading to the students of Grade One in Qinghua University in 2001. 62 students with low language proficiency participated in the study. The study consisted of two parts. One focused on metacognitive strategy training and the other was an investigation used to find out the effectiveness of the training. The students were trained on four metacognitive strategies, namely being aware of learning process, self-evaluation, establishment of objectives, and planning. The finding showed that most student's metacognitive awareness and ability to use those strategies had been enhanced.

At present, there are abundant studies on learning autonomy and metacognitive strategies. But few of them are specifically on the training of metacognitive strategies for promoting learning autonomy to the students who are in the Vocational \& Technical School. The present study aims to first investigate the status qua of the students' learner autonomy, then explore 
how to promote students' LA through metacognitive strategy training. I focused the training on the following four aspects: setting goals, planning, monitoring and evaluation.

\section{Present study}

\subsection{Subjects}

The participants of this study were 160 students of the first-year student who majored in logistics in the Ningxia Vocational \& Technical College They enrolled in the autumn of 2013. The subjects were assigned into two different classes, which were considered to be similar according to the results of the entrance examination. To ensure that the two classes were as homogeneous as possible, we gave the subjects a language proficiency test. The result showed that there was no significant difference between two classes in language proficiency. Then classes one was randomly selected as the control class (CC) and class two as the experimental class (EC). The EC and CC classes are taught by author herself. They followed the same curriculum with 4 English lessons each week. The subjects of the experimental group were given metacognitive strategies instruction as well as normal teaching contents while the control group was instructed as usual.

\subsection{Instruments}

Three instruments were used in this study. One was pre-test, the second one was language proficiency post-test, which was conducted after metacognitive strategy training with the purpose of investigating whether there existed significant differences between two classes. The third was questionnaire-"Learning Autonomy Questionnaire" which consists of 14 items which fall into 3 strategy groups: Planning, Monitoring and Evaluation. Likert's 1-5 scales ranging from "never" to "always" are also provided.

\section{Procedures}

\subsection{Awareness raising}

The first step in this study is to change students' attitudes to autonomy and strategy training because it is always agreed that Chinese students depend much on their teachers and hold passive attitudes to autonomy.

\subsection{Training materials and training contents}

This metacognitive strategy training was embedded in formal classroom settings. The materials we used in the training were textbooks $<<$ New Practical English $>>$ for First-year student on our college which was published by Higher Education Press. We used the textbook as the material with an important and obvious purpose. Strategy training is combined with student's learning experience, it will become easy for students to find the importance of strategies and they will be more ready to participate in the training program. $\mathrm{g}$,

4 Present study

\subsubsection{Setting goals}

Students in my college often have some difficulty in setting their learning goals. From this point of view, setting goals by students themselves is the first step towards autonomous learning. Goals may be long-term or short-term., Only when learners set a practical and meaningful goal by themselves can they make correct learning plans and select suitable learning materials so as to shorten the gap between themselves and other students more efficiently.

\subsubsection{Planning}

After setting goals, what students should do is to plan their learning according to the goals Similar to goals, plans can be long and short. For instance, a long-term plan may be "How should I learn English in the following two years in order to meet the demand the future job."; or the short-term plan may be "I will remember 10 words every day in order to pass the exam to be held next week".

\subsubsection{Self-evaluating}

Diaries or journals can help learners evaluate their progress also the students are encouraged to test themselves by doing relevant exercises or text papers which will be downloaded from Internet. It's easy approach for students to know their performance of English.

After setting goals, if students can keep monitoring their learning process and evaluating their learning outcomes, they are likely to find their problems. Then 
they will reconsider their learning plans to prepare for the possibly coming failure. In this way, examining their learning plans, adjusting their learning strategies, reflecting, self-managing and then reaching their goals consist of a complete and fine circulation.

4.3 The application of the CALLA model to metacognitive strategy training[4]

The Cognitive Academic Language Learning

\section{Description}

Preparation Learning by identifying students' prior knowledge of a topic and evaluating their current use of learning strategies, teachers can diagnose the needs of their students for strategies instruction.

Presentation -This phase focuses on explaining and modeling learning strategies. The teacher talks about the characteristics, usefulness, and applications of a strategy by modeling how he or she uses it.

Practice In this phase, students have the opportunity to practice the learning strategy with an authentic learning task. The practice is usually done collaboratively.

Evaluation $\cdot$ This phase provides students with opportunities to evaluate their own success in using learning strategies and to develop metacognitive awareness of their own learning process.

Expansion In this phase students make decisions about the strategies that they find most effective. They use these strategies in new contexts and in other classes, and devise their own individual combinations and interpretations of learning strategies.
Approach (CALLA)which was developed by O'Malley\&Chamot, is an instructional model for second and foreign language learners based on cognitive theory and research. CALLA integrates instruction in provides a useful framework for teaching language learning strategies. The sequence provides a five - phase recurring cycle for introducing, teaching, practicing, evaluating, and applying learning strategies.

\section{Metacognitive strategies}

Selective attention(deciding to attention to specific aspects of language input)

Advance organizer(main idea);

Selective attention;

Self-monitoring( checking

Intonation/pronunciation);

Self-monitoring( checking if they are right in attending to language points)

Advance prepation(rehearing the language needed)

Self-evaluation

Advance preparation

Self-monitoring 


\subsection{Data collection and analysis}

In order to guarantee the authenticity and validity, the students were made aware of the significance of the survey and required to complete the items according to their actual circumstances within 25 minutes. After collecting the questionnaire responses and the results of English replacement test, the writer analyzed all the data by using SPSS 19.0 for windows and adopting such statistical techniques as simple descriptive statistics, T- test and correlation analysis.

table 1.The results of the pre-test

\begin{tabular}{|l|c|c|c|c|c|c|c|}
\hline & Class & $\mathrm{N}$ & Mean & Std. Deviation & $\mathrm{t}$ & $\mathrm{df}$ & Sig. (2-tailed) \\
\hline Pre-test & $\mathrm{CC}$ & 80 & 58.4250 & 6.9647 & 0.896 & 78 & 0.373 \\
\hline & $\mathrm{EC}$ & 80 & 56.9250 & 7.9691 & & & \\
\hline
\end{tabular}

From the Table, it can be seen that the mean score of the E-class is quite on the intimate terms with that of C-class. The mean score of the E-class was 56.93 while
58.43 in the CC. $\mathrm{N}$ stands for the number of students in the E-class and the C-class.

Table 2The result of the post-test

\begin{tabular}{|l|c|c|c|c|c|c|c|}
\hline & Class & $\mathrm{N}$ & Mean & Std. Deviation & $\mathrm{t}$ & $\mathrm{df}$ & Sig. (2-tailed) \\
\hline Post-test & CC & 80 & 57.8000 & 10.0975 & 3.497 & 78 & 0.001 \\
\hline & EC & 80 & 65.3500 & 9.1890 & & & \\
\hline
\end{tabular}

In the table above, EC stands for the post-testing scores of the E-class, and $\mathrm{CC}$ stands for that of the C-class. According to the table, it can be seen that the mean score of the E-class in the post-test is 65.350 , and the score of the C-class is 57.800. It is obvious that the degree of the mean scores increase of the E-class is much higher.

Table3; Comparison of metacognitive Strategy use Frequency between EC \&CC:

\begin{tabular}{|l|l|l|l|l|l|l|}
\hline Variables & $\begin{array}{l}\text { Mean of } \\
\text { EC }\end{array}$ & SD of EC & $\begin{array}{l}\text { Mean of } \\
\text { CC }\end{array}$ & SD of CC & $\mathrm{t}$ & $\mathrm{p}$ \\
\hline $\begin{array}{l}\text { Overall } \\
\text { strategies }\end{array}$ & 3.62 & 0.432 & 2.74 & 0.366 & 7.686 & 0.000 \\
\hline Planning & 3.50 & 0.434 & 2.76 & 0.387 & 6.308 & 0.002 \\
\hline Monitoring & 4.12 & 0.665 & 2.72 & 0.830 & 6.578 & 0.000 \\
\hline Evaluation & 3.92 & 0.953 & 2.60 & 1.000 & 4.776 & 0.000 \\
\hline
\end{tabular}

Notes: 1 . The difference is statistically significant when $\mathrm{p}<0.05$.

As it is shown in Table 3, in respect of the overall strategy use, there is a statistically significant difference between $\mathrm{EC}$ and $\mathrm{CC}(\mathrm{p}=0.000)$, with the mean value of the former being much higher than that of the latter. This shows that EC use the overall strategies more frequently than CC. All the 3 strategy groups used by EC are significantly different from those used by $\mathrm{CC}$ ( $\mathrm{p}=0.000$ in the three cases). The 
biggest difference lies in monitoring $(\mathrm{t}=6.578)$, and then comes planning $(\mathrm{t}=6.308)$ and evaluation $(\mathrm{t}=4.776)$. This finding indicates that $\mathrm{EC}$ have more frequent use of the 3 strategy groups especially monitoring. 5. Conclusion

\section{Conclusion}

According to the experiment and the statistical analysis of the data collected, we can come to the following findings:

1. Learner autonomy, to some extent, can be fostered in the vocational \& technical classroom teaching . Through a series of metacognitive strategies training。, the students gradually learn to take responsibility for their learning, for example, setting their learning goals; making their learning plans; monitoring their learning process; adjusting their learning strategies; evaluating their learning results and searching for information needed etc, and finally become the master of their own learning.

2.Learner autonomy correlates with the training of metacognitive strategies. The effectiveness of metacognitive strategies training can result in the development of students' learner autonomy.

\section{Limitations}

First, the present research examined 160 students from the same school, thus, the application of the results to the whole group at other schools may be limited. Consequently, it is difficult to draw strong generalizations due to the limited number of subjects chosen in this survey. Second, another limitation comes from the limited duration of the metacognitive training. 4 class-hours every week in only one term is obviously not adequate for such a complex processing of LA to take more obvious effect on the subjects. Therefore, there is a need to conduct a similar but larger study in the future practice.

\section{Acknowledgement}

Fund Project: 2013 annual Ningxia science and technology research project (project number: NGY2013150)

Moderator: Guo Dongping

\section{References:}

[1] Holec, H (1981) Autonomy and Foreign Language Learning [M] Oxford: Pergamon Press

[2] Littlewood, W (1999) Defining and Developing Autonomy in East Asian Context Applied Linguistics[J] 20 (1) 71-94

[3] O’Malley, J.M. \& Chamot, A(1990) Learning Strategies in Second Language Acquisition [M] Cambridge University Press: 201-203

[4] Chamot, A. U.\&O'Malley, 」.M.(1994).The CALLA handbook: Implementing the cognitiveacademic language learning approach. White Plains, NY: Addison Wesley Longman.National Capital Language Resource Center (2002). The elementary immersion learning strategies resource guide. Washington, DC:NCLRC.

[5] Ji Kangli (2002),Metacognitive Strategy training in EFL learning [J] Foreign language World, 3:20-26 